\title{
Sintaxe e prosódia: antissimetria, hierarquia e isomorfismo
}

\author{
Syntax and prosody: antisymmetry, hierarchy and isomorphism
}

1 Doutor em Linguística com ênfase no modelamento computacional de aquisiçâo de primeira língua. Tem interesses também em teoria gramatical, em particular sobre questões envolvendo interfaces. Atualmente faz pos-doutorado no Departamento de Linguística da Universidade Estadua de Campinas (com bolsas$$
\text { 13/18090-6 e 14/17172-1) }
$$

pablofaria@gmail.com
RESUMO: Considero aqui duas propostas teóricas importantes na tradição da gramática gerativa, a saber, a de Kayne (1995), sobre a antissimetria da sintaxe, e a de Selkirk (1980), sobre a teoria de domínios prosódicos, ambas desenvolvidas em bases completamente independentes. 0 objetivo do artigo é demostrar que há uma relação fundamental entre os fenômenos que estas duas propostas captam, uma relação forte de causa e consequência. Argumentar, em suma, a favor da ideia de que os domínios prosódicos hierárquicos são uma expressão dos domínios hierárquicos estabelecidos na estrutura sintática, que há isomorfismo sintático e prosódico e, consequentemente, que esta propriedade deve ser explorada como forma de avaliar representações sintáticas. Em outras palavras, propriedades prosódicas podem ser úteis na escolha entre duas representações sintáticas concorrentes de uma expressão, na ausência de outros critérios independentes.

PALAVRAS-CHAVE: Sintaxe; Antissimetria; Hierarquia prosódica; Isomorfia.

ABSTRACT: Here I consider two important theoretical proposals of generative grammar tradition, both developed on independent grounds: Kayne (1995), about the antisymmetric character of syntax, and Selkirk (1980), about the theory of prosodic domains. The goal in this paper is to demonstrate that there exists a fundamental relationship between these two theoretical proposals, one of cause and consequence. I argue in favor of the claim that hierarchical prosodic domains are an expression of hierarchical domains established within syntactic structures and that, as a consequence, there is isomorphism between syntax and prosody and it should be explored as a way of evaluating hypothetical syntactic representations. In order words, prosodic properties may be useful in choosing between two competing syntactic phrasings of an expression when no other independent criteria is available.

KEYwoRDS: Syntax; Antisymmetry; Prosodic hierarchy; Isomorphy. 


\section{Introdução}

homsky 1995 (p.186-187) propõe que a sintaxe (ou "sistema computacional" da linguagem) seria a responsável por derivações que determinariam expressões linguísticas. Para isso, cada derivação partiria de um conjunto pré-selecionado de itens do léxico. Uma expressão linguística, afirma Chomsky, seria "uma realização ótima de condições de interface [Conceitual-Intencional (C-I) e Articulatório-Perceptual (A-P)]”. Por "realização ótima", Chomsky entende expressões que satisfaçam as condições e que sejam geradas da maneira "mais econômica".

Portanto, no modelo proposto por Chomsky, a sintaxe é quem responde a demandas das interfaces C-I e A-P, doravante PF ${ }^{1}$. É desta premissa, inerente à arquitetura mental da faculdade da linguagem proposta por Chomsky, que advém uma série de dispositivos teóricos, como por exemplo a distinção entre traços fortes e fracos (ou não-fortes), justamente como resposta a particularidades específicas à interface PF (traços fortes - determinados por PF - disparariam processos sintáticos antes da derivação chegar até lá). Consequentemente, estabelece-se uma espécie de "mão-dupla" entre a sintaxe e a interface $\mathrm{PF}$, com a sintaxe produzindo efeitos na interface $\mathrm{PF}$ e, ao mesmo tempo, com PF demandando processos particulares na sintaxe.

Compreende-se, assim, o surgimento de abordagens teóricas que enfraquecem a distinção modular entre sintaxe e fonologia/morfologia, como a Morfologia Distribuída (1993), visto que, na perspectiva proposta por Chomsky, os processos nestes dois níveis parecem entrecruzar-se. Mais ainda, a própria assunção de que a derivação sintática seria antecedida pela formação de uma numeração (composta por itens lexicais) e operaria sobre esta, poderia levar à conclusão forte de que a sintaxe não seria nada mais do

1 Por ser a sigla mais comumente utilizada. que um subconjunto particular de processos inseridos num conjunto global de operações morfológicas. Nada impede que seja assim, afinal. Porém, esta conclusão, parece ir na direção oposta à ideia de centralidade e universalidade da sintaxe, visto que é justamente na morfologia/fonologia que as línguas mais se diferem e de maneiras arbitrárias. Portanto, se queremos manter e dar força à ideia de uma gramática universal, à despeito das disparidades morfofonológicas das línguas, parece mais interessante mantermos uma distinção mais clara entre o módulo sintático e os demais.

Para tal, neste artigo exploro um caminho alternativo, questionando a própria premissa chomskiana de que a sintaxe deve satisfazer condições da interface PF. Neste trabalho não discutirei a relação da sintaxe com a interface C-I, que acredito poder também ser repensada em diversos aspectos, mas que não tem relevância para a presente discussão. Quero propor, nas sessões que seguem, que, ao contrário do que se tem pensado, é a interface PF que deve responder a demandas de interface com a sintaxe. Portanto, a relação inverte-se, quando se considera que a sintaxe deveria responder à $\mathrm{PF}$, ou deixa de ser bidirecional, para aqueles que assim a consideravam.

Para justificar esta mudança no estado de coisas, vou discutir como um aspecto (ou propriedade) da interface $\mathrm{PF}$, a saber, a hierarquia prosódica como apresentada em Selkirk (1980) (com eventuais referências a LIBERMAN \& PRINCE, 1977, e NESPOR \& VOGEL, 1986), pode ser vista como um reflexo de propriedades da sintaxe, especialmente as propriedades formais propostas em Kayne (1995), em que o autor discute a antissimetria da sintaxe. ${ }^{2}$ Estas são propostas com motivações completamente independentes. Por esta

${ }_{2}$ Trabalhos recentes sobre a interface sintaxe-prosódia, tais como os de Michael Wagner sobre prosódia e recursividade e as formulações mais recentes da teoria de Elisabeth Selkirk acabaram por ficar de fora do cerne da presente discussão. Porém, um estudo preliminar me leva a supor com alguma con do cerne da presente discona confiança que o cerne dos argum posterior.
ratur 
razão, ao propor uma relação de necessidade entre elas, acredito fornecer um argumento convincente em favor da mudança de perspectiva, ou seja, na forma como vemos a relação entre a sintaxe e a interface PF.

Quanto à organização deste artigo, na sessão 1 apresento brevemente as duas propostas, de Kayne e de Selkirk. Na sessão 2 mostro que a propriedade de antissimetria, antes de derivar precedência linear, deriva hierarquia, neste caso, a prosódica. Na sessão 3 discuto a noção de "opacidade hierárquica" e como esta tem papel fundamental na relação entre a hierarquia prosódica e a antissimetria da sintaxe. Por fim, faço algumas considerações finais, sobre outras possíveis consequências dessa proposta, especialmente, sobre uma possível consequência metodológica, para os estudos da sintaxe: a fonologia, mais particularmente a teoria de domínios prosódicos, poderia - e talvez devesse - ser uma ferramenta fundamental para a avaliação das inúmeras representações sintáticas propostas na tradição gerativa, na medida em que tais representações fossem estruturalmente equivalentes àquelas que a primeira propõe. Além disso, discuto também algumas consequências para os estudos de aquisição da linguagem.

\section{A antissimetria da sintaxe e a hierarquia prosódica}

\subsection{Kayne e a antissimetria da sintaxe}

Kayne (1995) apresenta uma proposta concisa e cuidadosamente formalizada, cuja consequência é colocar severas restrições sobre as representações sintáticas em geral, no que tange ao ordenamento nas línguas. Para Kayne, deriva-se da antissimetria da sintaxe que adjuntos e especificadores (para ele, apenas instâncias de adjuntos ${ }^{3}$ ) ficam à esquerda

3 Ponto polêmico de sua proposta, dado o importante papel desempenhado pela distinção especificador/
adjunto, na teoria gerativa, mesmo que o estatuto dos adjuntos nunca tenha sido totalmente esclarecido, sendo tomado como uma espécie de caso elsewhere. do núcleo, e o complemento à direita. Assim, Kayne se compromete com uma forte afirmação, a saber, a de que nenhuma língua é uniformemente núcleofinal, embora os núcleos visíveis possam aparecer em posição final (através de operações de movimento).

Vale a pena comentar esta afirmação, visto que ela tem alguma relação com a prosódia das línguas. Ela não deriva de nenhum modo diretamente de sua proposta, ou seja, não surge como uma consequência ou previsão dela (ver a definição do axioma abaixo). Por este motivo, me permito discordar de Kayne, por duas razões que comento a seguir. Primeiramente, embora tenha de fato sido tratada como uma espécie de mapeamento do ordenamento linear em muitas análises e aplicações, a ordem em que os elementos da estrutura interna de um sintagma XP, como proposta pela Teoria X, estão organizados, nunca foi direta e explicitamente vinculada à propriedade de ordem linear. Daí a força da noção de c-comando, cuja definição se baseia apenas em propriedades hierárquicas, sendo a ordem dos elementos irrelevante.

Em segundo lugar, Kayne parece ignorar uma possibilidade mais simples e elegante para explicar as diferentes ordens exibidas pelas línguas: tanto uma ordem quanto outra(s), pode ser obtida a partir de uma mesma estrutura hierárquica, bastando para isso aplicar diferentes algoritmos de linearização (que poderiam, por exemplo, ser parametricamente configurados). 0 "custo" de tal abordagem seria significativamente menor, quando comparado aos inúmeros movimentos necessários para derivar a ordem, segundo o que Kayne assume. Com isso, é possível mantermos uma visão mais abstrata da estrutura sintática, em que não há "ordem" na hierarquia, enquanto um artefato mental.

Propriedades como "direita" ou "esquerda", "inicial" ou "final", parecem entrar em questão apenas quando representamos as estruturas sintáticas num plano bidimensional, para fins de análise. Não parece 
adequado, portanto, estendermos propriedades extrínsecas como estas às representações abstratas relevantes à sintaxe. Curiosamente, esta visão é até mais condizente com a proposta de Kayne, em que ele mostra ser possível derivar a ordem linear dos elementos terminais da árvore a partir da assimetria de c-comando, ou seja, para a sintaxe apenas a hierarquia é relevante, sendo a ordem linear dos elementos terminais relevante apenas em PF. Portanto, sigo apenas com o essencial da proposta de Kayne.

Para o autor, o c-comando assimétrico na sintaxe é invariavelmente mapeado em precedência (ou, em minha visão, também sucessão) linear, em PF. Kayne observa que a relação de ordem linear (L) dos símbolos terminais de uma sentença exibe três propriedades:

(i) é transitiva (se xLy e yLz, então xLz);

(ii) é total (para qualquer $\mathrm{x}, \mathrm{y}$ distintos, ou xLy ou yLx);

(iii) é antissimétrica (não pode xLy e yLx).

Uma pergunta possível, portanto, é se estas propriedades teriam uma contraparte estrutural, na sintaxe. Kayne observa que a relação de dominância entre não-terminais é transitiva e antissimétrica, mas não total: podem haver dois nós sem relação de dominância, num determinado marcador sintagmático. Porém, ele propõe que se restringirmo-nos apenas ao ambiente local de um dado nó $\mathrm{X}$ (i.e., os nós que dominam $\mathrm{X}$ ), teremos então a propriedade da totalidade: para os nós $\mathrm{Y}$ e Z (distintos), que dominam $\mathrm{X}$, ou $\mathrm{Y}$ domina $\mathrm{Z}$ ou $\mathrm{Z}$ domina $\mathrm{Y}$. Consequentemente, o mesmo vale para a relação de c-comando. Kayne conclui que há, portanto, uma relação entre a ordem linear de terminais e a relação local de não-terminais por c-comando, mediada pela relação linear local de dominância. Assim, Kayne propõe o axioma a seguir:
Seja A o conjunto de pares ordenados de nós não-terminais $\left\langle\mathrm{X}_{\mathrm{j}} ; \mathrm{Y}_{\mathrm{j}}\right\rangle$, tal que para cada $\mathrm{j}, \mathrm{X}_{\mathrm{j}}$ c-comanda assimetricamente $\mathrm{Y}_{\mathrm{j}}$. Seja $\mathrm{T}$ o conjunto de terminais e $\mathrm{d}(\mathrm{)}$ a relação de dominância de não-terminais sobre terminais

\section{Axioma da Correspondência Linear (LCA)}

$\mathrm{d}(\mathrm{A})$ é a ordem linear de T.

Kayne oferece o seguinte exemplo de aplicação do LCA: na árvore (1) abaixo, o conjunto A é formado pelos pares $\langle$ J,M $\rangle,\langle$ J, N $>,\langle$ J,P $>$ e $\langle$ M, P $>$. Como cada nó domina apenas um nó terminal, os pares de nós terminais definidos por d(A) são: $<\mathrm{j}, \mathrm{m}>,<\mathrm{j}, \mathrm{p}>\mathrm{e}<\mathrm{m}, \mathrm{p}>$. Assim, para o conjunto dos terminais $T=\{j, m, p\}$, temos a ordenação relativa completa entre seus elementos.

(1)

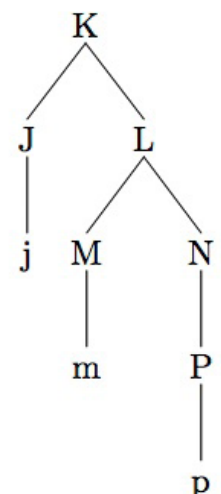

Kayne mostra que o LCA gera duas consequências desejáveis para a teoria linguística: (i) explica porque um núcleo não pode ser complemento de outro núcleo (com c-comando simétrico a ordem não poderia ser determinada), e (ii) portanto, explica porque um XP não pode ter dois núcleos $\mathrm{X}$, ou seja, um núcleo só pode ter como nó irmão, uma projeção 
máxima. Outra consequência importante é a de que todo XP deve possuir um núcleo. Há uma característica interessante derivada do modelo de Kayne, que é importante ressaltar: especificadores e adjuntos não são necessários, ou seja, não são primitivos da estrutura de um sintagma, como o são o núcleo e seu complemento ${ }^{4}$.

\subsection{Selkirk e a hierarquia prosódica}

Selkirk (1980) apresenta uma proposta teórica que a autora define como uma "elaboração ou revisão" da teoria desenvolvida em Liberman \& Prince (1977), que propuseram uma teoria métrica para representação de padrões de acento relativo no inglês, como alternativa mais racional ao tratamento segmental ou silábico que vinha sendo dado até então. Nos modelos silábicos, era proposto um traço acento de valoração $n$-ária, ou seja, seus valores variavam de 0 a $n$ (p.e., 5), no intuito de capturar as nuances acentuais em palavras, sintagmas e na sentença como um todo. Buscando racionalizar a intuição por trás desse tratamento "arbitrário", Liberman \& Prince propõem um tratamento relacional dos padrões acentuais. Os autores mostram que os padrões numéricos podem ser derivados da estrutura relacional, como mostra (2). Note que a árvore é binária, com os nós em cada nível rotulados como "s" (strong) e "w" (weak), determinando a acentuação relativa em todos os níveis.

\footnotetext{
${ }^{4}$ O complemento também não é necessário nesse sentido, mas se assumimos que questões de ordenamento se colocam apenas quando temos dois ou mais elementos, então o complemento se torna obrigatório. Um possível contra-argumento seriam as construções inergativas. Porém, a única justificativa para assumir que nessas construções se trata de um especificador e um núcleo é a ordem, pois do ponto de vista da análise puramente estrutural, não haveria diferença em considerar essas construções como estruturas núcleo-complemento.
}

(2)

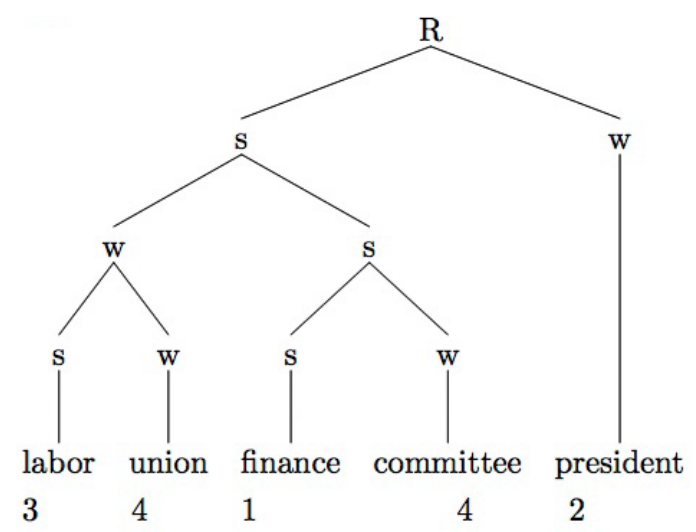

Embora a proposta de Liberman \& Prince tenha sido aplicada ao inglês, a intuição era a de que esta abordagem fosse adequada para as demais línguas. Os desenvolvimentos futuros dessa proposta - como os de Selkirk (1980) e Nespor \& Vogel (1986) - seguiram, portanto, nessa linha. Em sua proposta, Selkirk argumenta que a representação proposta em Liberman \& Prince é ainda muito empobrecida, pois não diferencia o que ela chama de "categorias prosódicas", a saber, "subunidades diferenciadas específicas de estrutura prosódica, que 'rotulam' os nós da árvore”. Assim, Selkirk propõe as categorias sílaba $(\sigma)$, pé $(\Sigma)$, palavra prosódica $(\omega)$, sintagma fonológico $(\varphi)$, sintagma entoacional (I) e enunciado (U). Além dessa elaboração, Selkirk vai argumentar contra a ideia de isomorfismo entre a estrutura prosódica e a sintática, assumida em Liberman \& Prince, além de não se comprometer (assim como Nespor \& $\operatorname{Vogel}^{5}$ ) com a binariedade da hierarquia.

Enquanto em Liberman \& Prince a motivação para a proposta da hierarquia prosódica se assentava basicamente nos padrões acentuais do inglês, Selkirk mostra que as categorias prosódicas se constituem em

5 As autoras fazem a ressalva de que este é um aspecto controverso e que, naquele momento, a discussão sobre ramificação binária x n-ária ainda estava em aberto (NESPOR \& VOGEL, 1986, p. 7). 
domínios nos quais se aplicam diversos fenômenos fonológicos, para os quais ela fornece alguns exemplos e inúmeros outros são fornecidos em Nespor \& Vogel (1986). Em (3) e (4), vemos um exemplo ${ }^{6}$ de estrutura sintática, como assumida por Selkirk, e prosódica, como proposta por ela (ver SELKIRK, 1980, p.28). O não-isomorfismo defendido por Selkirk fica evidente, por exemplo, na estrutura de Tuesday, which is a weekday, que não forma um constituinte (prosódico), como ocorre na sintaxe.

(3)

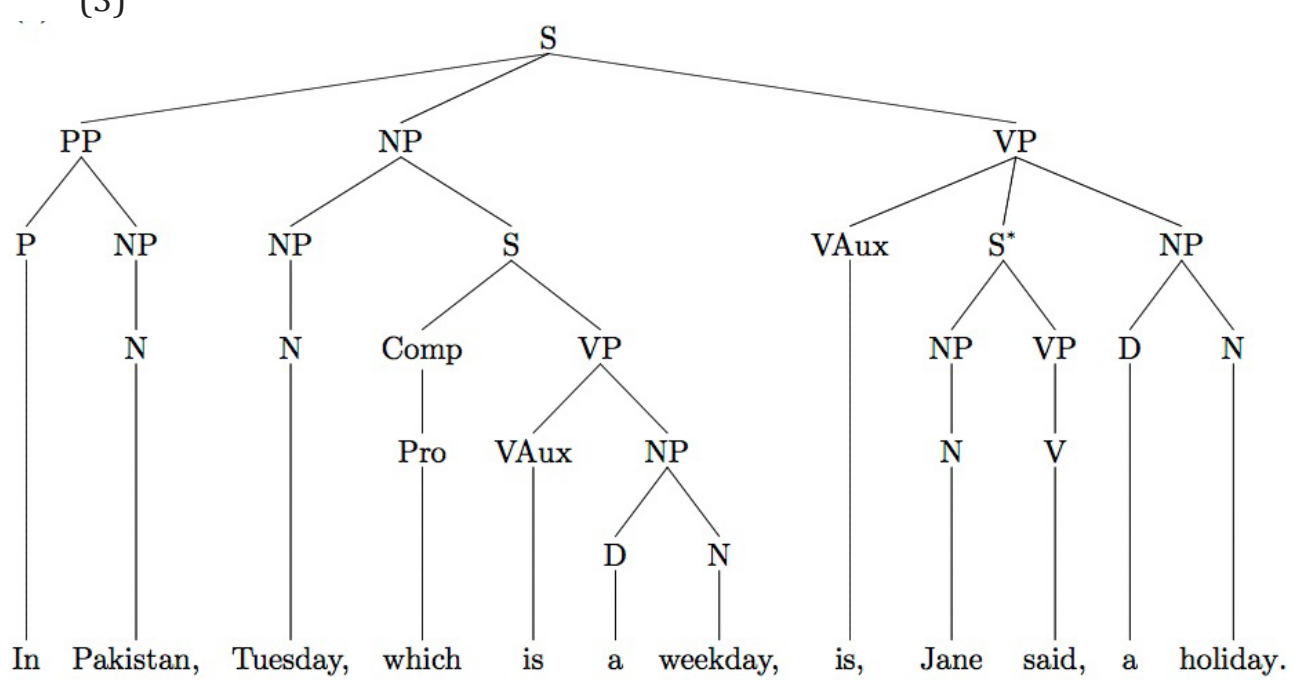

Nespor \& Vogel (1986), numa subsequente e abrangente elaboração dessa teoria, também enfatizam a não-isomorfia e ainda insistem em questões que envolvem inclusive a arquitetura da gramática. Segundo as autoras, a componente fonológica da gramática deve ter uma interface com a componente semântica, pois certas relações semânticas entre sentenças (por

${ }^{6} \mathrm{O}$ nó S*, em (3), aparece originalmente desconectado da árvore em Selkirk. Aqui, por questões técnicas, ele aparece conectado, mas deve ser interpretado como uma parentética. exemplo, relações lógicas) são necessárias para motivar alguns processos que ocorrem nos níveis mais altos da hierarquia prosódica (i.e., entre U's). Em relação à percepção da fala, elas ainda afirmam que é o conjunto de constituintes prosódicos - e não os sintáticos - que dão conta do primeiro nível de processamento.

(4)

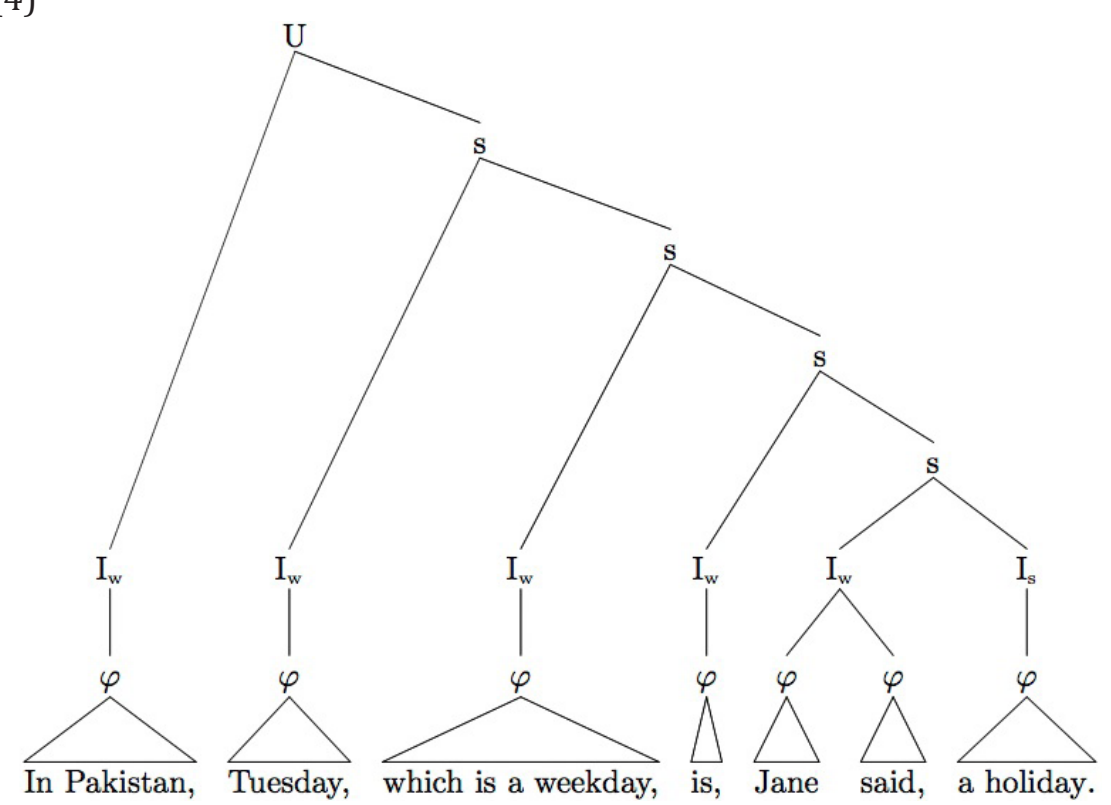

Todos os autores, no entanto, mantêm o princípio geral de organização dos níveis da hierarquia, que se baseia na oposição forte/fraco (em relação à proeminência relativa), mesmo em estruturas não binárias (em que, neste caso, entre os nós de um mesmo nível, apenas um seria forte, sendo os demais fracos). Vale ressaltar que há processos fonológicos específicos a cada nível prosódico. Como o que nos interessa aqui é a relação entre a estrutura sintática e a estrutura prosódica, vamos seguir Selkirk (1986), considerando apenas 
os domínios acima do pé e abaixo do sintagma entoacional (ou seja, a palavra prosódica e o sintagma fonológico). Selkirk propõe que as fronteiras destes domínios são definidas com base nas fronteiras dos sintagmas sintáticos, sem menção ao que ocorre em seu interior. Daí ser uma abordagem chamada de end-based $^{7}$.

\section{Antissimetria é hierarquia}

Antes de seguirmos para a proposta central deste artigo, farei alguns comentários sobre as consequências essenciais da proposta de Kayne. Embora o autor tenha enfatizado as consequências de sua proposta para a linearização, penso que seu grande valor reside nas consequências que gera para as representações sintáticas em geral. Kayne não deixa de notar isso, é claro, e dedica um capítulo à demonstração de como a Teoria $\mathrm{X}$ pode ser derivada de seu axioma, mostrando que esta não seria um primitivo da gramática, mas apenas a expressão de propriedades essenciais desta.

Quero, portanto, colocar uma ênfase ainda maior sobre este aspecto. Antes de qualquer consequência para a linearização, o que a proposta de Kayne mostra é que o caráter antissimétrico da sintaxe tem como consequências imediatas e fundamentais o estabelecimento de (i) estruturas hierárquicas e, especialmente, binárias, e (ii) o fato de que o núcleo é obrigatório e de que o complemento não pode ser outro núcleo. A consequência (i) é de uma importância fundamental para a teoria, embora na prática e em geral pareça ser tomada como um fato óbvio, por ser tão pouco enfatizada. Senão, vejamos.

Alternativamente, Nespor \& Vogel (1986) propõem uma abordagem em que a definição dos domínios leva em conta mais explicitamente elementos no interior do sintagma, como o núcleo, por exemplo.
A priori não há necessidade de se postular estruturas arbóreas e binárias, para representar as relações entre os elementos de uma sentença. Tanto é assim, que a teoria passou (e talvez ainda passe) por fases em que se adotavam representações n-árias, por exemplo, para os complementos de verbos ditransitivos, como dar ou colocar. Muitas vezes, decidir entre uma ou outra representação era apenas uma questão de conveniência. Isso sem falar em representações outras, que não as arbóreas, possíveis de serem elaboradas. Na ausência de restrições externas, nenhuma possibilidade é proibida a priori. Com a proposta de Kayne, no entanto, há uma restrição formal e motivada por propriedades da arquitetura da gramática, ou seja, são propriedades inerentes ao módulo fonológico (neste caso, propriedades relativas à linearização) as responsáveis por constringir representações sintáticas.

A segunda consequência, (ii), teve parte de sua importância avaliada por Kayne, ao vinculá-la à linearização dos terminais. Porém, vou mostrar que não é apenas este o papel de (ii). Na próxima seção, vou propor que esta assimetria entre os nós filhos de um nó qualquer, na sintaxe, é diretamente responsável pela oposição forte/fraco identificada em todos os diferentes níveis da hierarquia prosódica. Além disso, vou fazer a afirmação forte de que, ao contrário do que defende Selkirk e Nespor \& Vogel, há sim isomorfia entre os constituintes sintáticos e prosódicos e, mais do que isso, vou defender que esta isomorfia é tão necessária quanto o é a ordem linear que os elementos terminais apresentam, após a linearização.

\section{Um passo além}

\subsection{Uma premissa essencial}

Afinal, do que trata a sintaxe? Podemos dizer que a sintaxe trata de um conjunto de relações e propriedades abstratas entre elementos linguísticos, 
numa determinada disposição (i.e., quando compõem sentenças). Chamamos tais relações e propriedades de "abstratas", justamente por não serem, em geral, visíveis e codificadas nos elementos terminais discretos que compõem a sentença. Por outro lado, na linha teórica em que nos situamos (cf. CHOMSKY, 1995), adota-se um modelo no qual a representação sintática é "traduzida" em dois tipos de representações, uma de natureza lógico-semântica e outra - que nos interessa aqui - de natureza articulatório-perceptual.

Se há tradução neste sentido, portanto, devemos nos perguntar o que acontece com as relações e propriedades sintáticas que não aparecem codificadas (diretamente) nos elementos terminais. Ficam "perdidas" de alguma maneira? Esta seria uma possibilidade plausível, afinal é um fato comum que traduções (de um modo geral) sejam "incompletas", ou seja, quando comparamos o "original" com a tradução, identificamos omissões, inadequações e até distorções. O problema, no caso da linguagem, é que o falante não tem a sua disposição - principalmente quando destacamos demandas de aquisição da linguagem ${ }^{8}$ - o "original”, ou seja, não há como acessar diretamente a representação sintática de uma sentença. A única via de acesso à estrutura sintática (e, claro, à parte das propriedades semânticas e pragmáticas) é a representação (morfo)fonológica.

Estas propriedades abstratas, portanto, devem se refletir de algum modo na representação fonológica, sob pena de serem "perdidas", o que impediria uma correta análise sintática da estrutura (daí uma série de ambiguidades, quando tomamos sentenças escritas sem indicações de sua pronúncia efetiva). As distinções sintáticas não podem ser "opacas" em PF. Assim, vou assumir um princípio geral, possivelmente particular à faculdade da

\footnotetext{
8 Se para o falante adulto, o conhecimento das categorias lexicais pode ajudar na identificação de núcleos e complementos, o mesmo não pode ser dito de uma criança nos primeiros estágios de aquisição. Seria interessante, portanto, que a representação fonológica das estruturas produzidas pela sintaxe fosse igualmente útil tanto no período de aquisição, quanto para o falante adulto.
}

linguagem, que pode ser definido como segue e que coloca em relação direta as propriedades sintáticas destacadas na seção anterior e as propriedades dos domínios prosódicos:

\section{(5) Restrição sobre Representações Fonológicas (RRF)}

Na tradução de uma representação sintática $\mathrm{A}$ em uma representação fonológica B, as distinções hierárquicas e a assimetria núcleocomplemento não podem ser "opacas" em B.

A restrição acima traz algumas consequências, sendo a mais importante a de que a demanda de que a sintaxe atenda a requerimentos da interface PF se inverte: o que (5) estabelece é que a interface PF atenda a requerimentos da sintaxe, ou seja, represente por meios as relações e propriedades estabelecidas ali. Nas duas próximas subseções, argumento em favor de duas possíveis "traduções" nessa relação sintaxe-fonologia: a distinção forte/fraco como tradução da distinção núcleo/complemento e a isomorfia.

\subsection{As oposições forte/fraco nos níveis prosódicos}

A primeira consequência de (5) é provavelmente a mais intuitiva e direta: a representação fonológica precisa refletir esta simples distinção sintática entre núcleo e complemento. Os constituintes prosódicos apresentam, segundo as propostas indicadas neste artigo, uma oposição básica entre forte/fraco em todos os níveis prosódicos, distinção esta normalmente atribuída a uma tendência rítmica natural das línguas naturais. Podemos dar um passo razoável e assumir, na ausência de evidências em contrário, que este efeito de proeminência relativa é apenas reflexo da distinção núcleo/ complemento (até por isso uma "tendência natural"), pelo menos nos níveis da palavra prosódica e do sintagma fonológico. 
Como um passo mais especulativo, podemos até cogitar a possibilidade de que um processo semelhante se dê no interior da palavra (ou seja, haveria uma "sintaxe interna às palavras", traduzida também na fonologia), visto que os padrões de proeminência relativa também aparecem nos níveis prosódicos abaixo da palavra prosódica. Porém, essa possibilidade está fora do âmbito deste artigo e fica por ser investigada futuramente.

\subsection{A isomorfia sintático-prosódica}

Da perspectiva proposta neste artigo, o isomorfismo aparece como a hipótese nula, a ser confirmada ou falseada. Portanto, talvez a melhor forma de argumentar pelo isomorfismo, seja destacar um contraexemplo de isomorfismo apresentado por Selkirk, como ilustrativo do argumento que eu proponho para os demais contraexemplos apresentados por ela e também em Nespor \& Vogel, para mostrar que, na verdade, tais evidências são baseadas em representações sintáticas hipotéticas e, portanto, passíveis de contestação, mesmo em bases puramente teóricas (tanto as de então, quanto as atuais).

Em primeiro lugar, vale ressaltar que as representações sintáticas assumidas em ambos os trabalhos foram baseadas na Teoria de Regência e Ligação e nas versões iniciais da Teoria X. Se considerarmos ainda o quanto a teoria sintática se desenvolveu desde então, principalmente no que tange às representações sintáticas, temos aí boas razões para reanalisar os argumentos contrários ao isomorfismo, fornecidos pelas autoras, sob outra ótica. Em segundo lugar, vale ressaltar que os domínios prosódicos podem apresentar sintagmatização (i.e., estruturação em constituintes) variável. Tal variação pode incidir sobre os domínios entoacionais (I's) (cf. SELKIRK, 1980, p. 21-23) ou mesmo no nível dos sintagmas fonológicos ( $\varphi$ 's), num processo chamado de reestruturação (cf. NESPOR \& VOGEL, 1986).
Portanto, é possível contestar tais contraexemplos em duas direções: ou a representação sintática pode ser revista, ou a própria representação fonológica. Ao que tudo indica, em ambos os trabalhos, as autoras parecem assumir que, mesmo com variação na organização dos domínios prosódicos, a representação sintática é a mesma. Ou seja, seria possível uma relação de 1 x n (estrutura sintática x estruturas prosódicas). Embora concorde com essa observação, penso que é importante não descartar a possibilidade de que certas variações na estrutura prosódica possam servir como evidência de que a organização sintática de uma dada sentença possa ser distinta da tradicionalmente assumida. Como exemplo, vejamos a sentença em (6) (cf. SELKIRK, 1980, p. 23), em que temos uma organização prosódica possível para a sentença em questão (há outras três configurações possíveis para os I's):

(6)

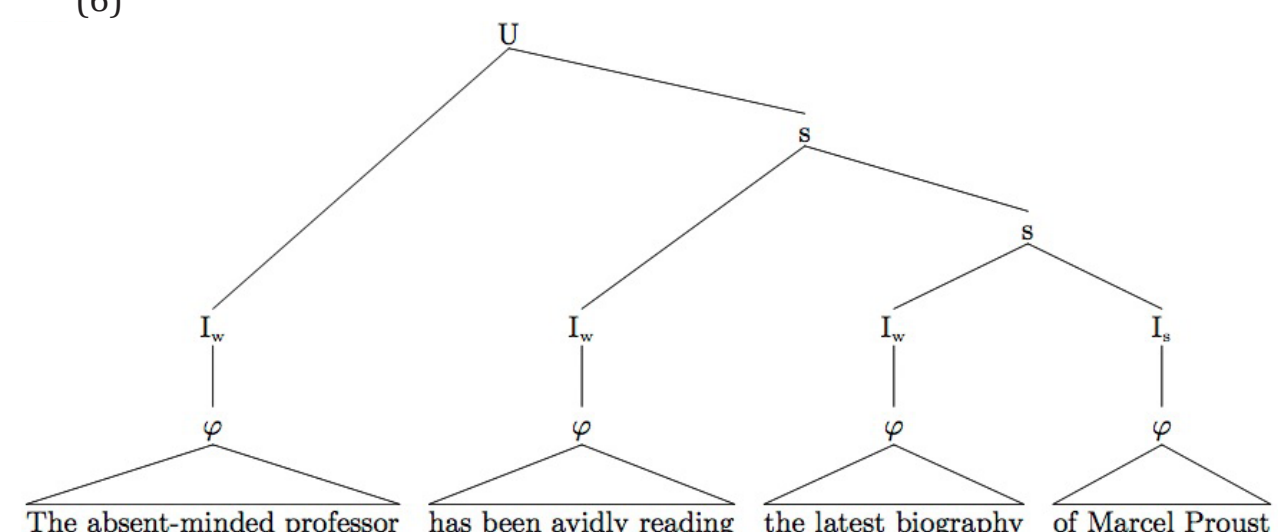

Normalmente, as representações sintáticas para esta sentença apresentam duas diferenças essenciais em relação à (6): primeiro, o sintagma nominal (DP) "the latest biography of Marcel Proust" costuma ser 
analisado como um único constituinte, como em (7)9; segundo, os auxiliares e o advérbio tenderiam a formar constituintes mais altos que o sintagma verbal (VP), como vemos em (8).

(7)

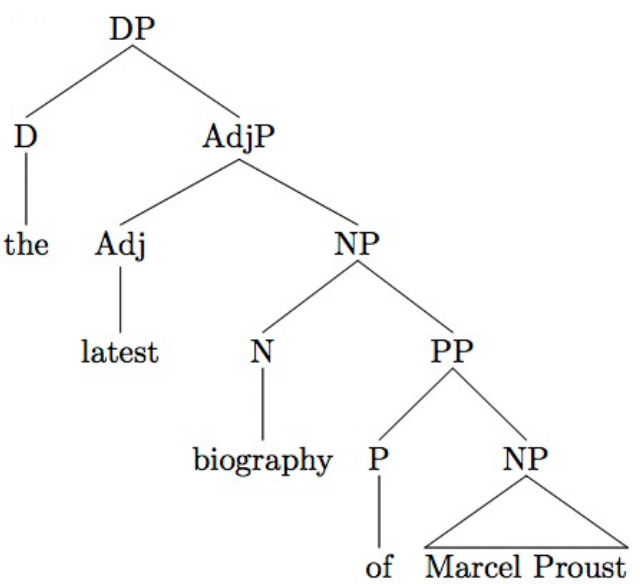

(8)

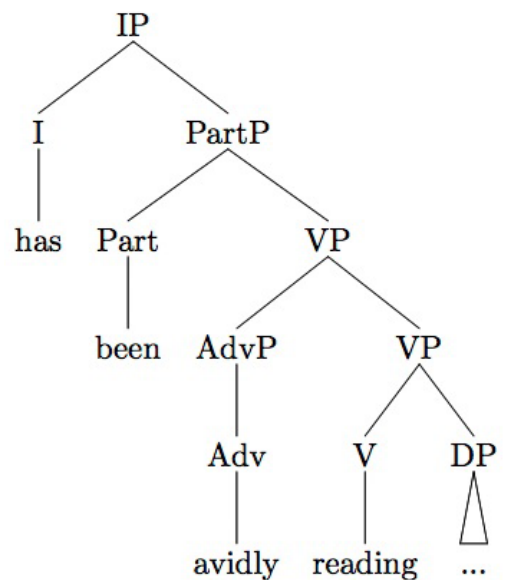

Como vemos, portanto, com base nestas representações só se pode concluir que não há isomorfia, se assumirmos que tal isomorfia deva se dar no nível dos sintagmas fonológicos. Se esta assunção puder ser enfraquecida, entretanto, nosso problema diminui. Se, por exemplo, pudermos assumir que a isomorfia pode (ou talvez deva) ser avaliada no nível entoacional máximo ${ }^{10}$, então obtemos a compatibilidade sem a necessidade de alterações nas estruturas envolvidas, com a ressalva de que, no caso de (8), será preciso assumir que projeções funcionais não contam para a determinação de sintagmas fonológicos independentes.

Se, no entanto, mantivermos a assunção de que a isomorfia deve ser avaliada com respeito aos sintagmas fonológicos, então nos vemos diante de consequências interessantes. Em relação à (7), por exemplo, supondo que o complemento nominal (PP) se adjunja ao DP como um todo, obtemos a compatibilidade. Embora certamente demande outros dados e evidências que a suportem, tal análise não é a priori inimaginável, especialmente quando se tem em mente que o próprio estatuto do nível "DP" é ainda objeto de discussão teórica.

No caso de (8), somos defrontados por um desafio maior, mas que traz reflexões interessantes sobre o papel de elementos funcionais. Estes elementos apresentam não apenas uma natureza sintática e semântica bastante particular, mas também costumam se comportar distintamente na fonologia, por exemplo, tendendo a se cliticizar, formando sintagmas fonológicos no domínio de um núcleo lexical. Portanto, podemos nos perguntar se tais elementos realmente disparam projeções sintáticas próprias, nos mesmos moldes das projeções de núcleos lexicais. Consequentemente, a combinação de um núcleo funcional com um núcleo lexical produziria uma projeção estendida deste último, uma ideia que não é nova (ver, por

${ }^{10}$ Isto é, o nível mais alto possível, abaixo de U. 
exemplo, GRIMSHAW, 2000). Até aqui, nenhuma novidade. Agora, tomemos a árvore em (8'):

$\left(8^{\prime}\right)$

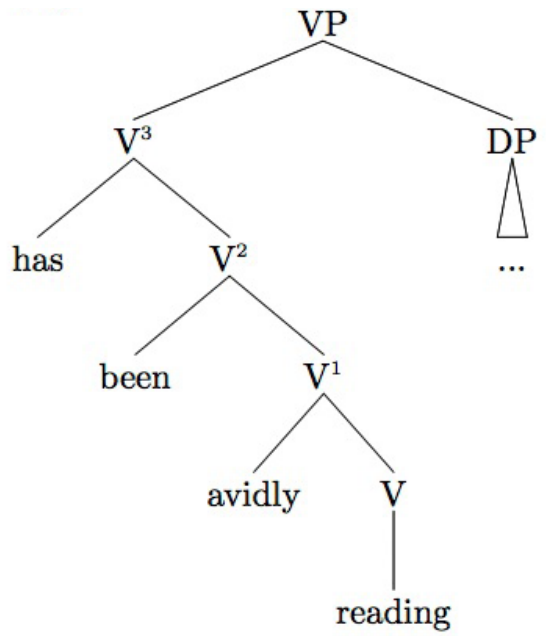

Note que (8'), devido a uma composição diferente da estrutura, é compatível com os sintagmas fonológicos em (6). No entanto, estamos de frente a uma estrutura significativamente distinta da tradicionalmente assumida, em (8). A questão é se há razões teóricas e empíricas que permitam descartar uma em favor da outra. Se não houver, então a compatibilidade isomórfica vem em favor de (8'). Certamente, há consequências formais e empíricas a serem derivadas de cada opção estrutural. Tal investigação, entretanto, está fora do escopo deste artigo. No que segue, me concentro no impacto de (8') sobre a teoria de Kayne.

O LCA se assenta, como já vimos, na distinção núcleo/projeção máxima. Isso poderia gerar um problema para (8'), visto que não está claro qual o estatuto dos núcleos funcionais em relação ao verbo. Se não projetam, poderia ser o caso de que estejam aí como múltiplos adjuntos ou especificadores, o que estaria em conflito com a proposta kayniana. Para resolver este problema, seria necessário assumir uma versão mais derivacional do LCA, em maior consonância com pressupostos minimalistas. Neste caso, "reading" se comportaria como projeção máxima, com respeito ao núcleo funcional. Porém, como já propomos, o objeto formado pela combinação ("merge") seria verbal. Após derivar "has been avidly reading", a categoria $\mathrm{V}^{3}$ se comportaria como núcleo, por ocasião da combinação com o complemento DP, mantendo intactas as previsões do LCA, permitindo o ordenamento de todos os terminais ${ }^{11}$ :

- O conjunto A seria formado pelos pares $\langle$ has, been $>,<$ has, avidly $>,<$ has, $V>$, <been, avidly $>$, <been, $V\rangle$, <avidly, $V\rangle e\langle V 3,[D P \ldots]\rangle$;

- Os pares de nós terminais definidos por d(A) seriam, portanto, $<$ has, been>, <has, avidly>, <has, reading>, <been, avidly>, <been, reading>, $<$ avidly, reading $>e<$ has been avidly reading, $[D P . .]>$.;

- E, assim, teríamos a ordem relativa completa entre os elementos terminais do conjunto $\mathrm{T}=\{$ has, been, avidly, reading, [DP...] $\}$.

Temos então um quadro geral que, embora assentado sobre uma série de assunções para as quais é necessário um adequado suporte teórico e empírico, consolida e põe em relação propriedades da estrutura sintática e propriedades prosódicas das línguas. Vale ressaltar que o mesmo tipo de raciocínio proposto com relação à (8') poderia ser estendido aos demais contextos envolvendo categorias funcionais e lexicais.

\section{Considerações finais}

Com a exposição acima, espero ter atingido os objetivos deste artigo, que eram (i) mostrar a plausibilidade de assumir que a propriedade de

11 Optei por simplificar a apresentação, não mencionando os elementos internos ao DP. 
antissimetria da sintaxe é que determina as distinções hierárquicas na prosódia, e (ii) mostrar que é possível assumir a isomorfia entre constituintes sintáticos e prosódicos e, mais, argumentar pela necessidade de tal isomorfia, enquanto meio de atender à RRF em (5), que postulo como um princípio geral da gramática. Certamente, a discussão feita neste artigo se constitui apenas em um primeiro passo em direção a uma teoria que articule de modo pleno e sistemático a relação entre a sintaxe e fonologia.

Antes de concluir, gostaria de reforçar algumas consequências dessa proposta, além de apontar algumas outras. Primeiro, gostaria de enfatizar sua consequência metodológica: o fato de que, no quadro que proponho, a interface PF deva atender a demandas da sintaxe, não determina que, nas tarefas de análise teórica, as representações fonológicas devam ser submetidas às sintáticas; ao contrário, diante do fato de que as representações fonológicas possuem correlatos acústicos e, portanto, diretamente verificáveis empiricamente, devemos considerar seriamente a possibilidade de que estas representações é que devam ser a base para a avaliação das representações sintáticas. Um exemplo de como tal metodologia pode contribuir para as reflexões sobre a sintaxe foi oferecido acima, na discussão da estrutura alternativa ( $\left.8^{\prime}\right)$.

Em segundo lugar, vou trazer aqui a observação de Nespor \& Vogel (1986, p. 2), que afirmam que a construção da hierarquia prosódica não é de natureza recursiva, como na sintaxe. Isso em nada contradiz o quadro que proponho aqui. 0 que se demanda da hierarquia prosódica não é uma codificação estritamente equivalente da estrutura sintática, mas sim uma codificação que não torne opacas as propriedades hierárquicas estabelecidas na sintaxe.

Por fim, do ponto de vista da aquisição da linguagem, o quadro apresentado ressalta o papel fundamental da prosódia, como gatilho nos primeiros estágios de aquisição, como o acesso principal da criança aos contornos da estrutura sintática. Tanto mais fundamental será a prosódia, quanto mais isomorfa ela for, em relação à sintaxe.

Nada de novo, tampouco, como mostra largamente Mazuka (1998) (e outros estudos indicados ali) sobre o papel da prosódia nos primeiros estágios da aquisição. Ademais, segundo Liberman \& Prince (1977), estudos de percepção mostram que sentenças em que as sílabas são todas substituídas por uma sílaba única (p.e., "ma”) são perfeitamente analisáveis pelos falantes, quanto à hierarquia prosódica. Ou seja, mesmo após o período de aquisição, os contornos estruturais continuam sendo fundamentais no processamento linguístico e, tudo leva crer, ao parsing gramatical. Diante destes fatos, experimentos psicolinguísticos tanto em adultos, quanto em crianças em fase de aquisição, poderão produzir evidências empíricas relevantes para a sustentação da presente proposta.

Finalmente, essa discussão em torno do papel da sintaxe na prosódia e em torno da natureza da representação prosódica na mente do falante tem sido tratada em trabalhos mais recentes, em particular, trabalhos da própria Elisabeth Selkirk e também de Michael Wagner. Estudos preliminares me permitem supor que há interessantes aspectos congruentes entre o que é apresentado aqui e as propostas específicas destes autores. Com o objetivo de investigar mais a fundo essas relações, está sendo iniciado um estudo que permitirá reavaliar o presente trabalho à luz das discussões mais recentes na literatura da área.

\section{Agradecimentos}

Gostaria de agradecer em especial à FAPESP - Fundação de Apoio à Pesquisa do Estado de São Paulo - pela bolsa de doutorado durante o qual este trabalho foi desenvolvido. Agradeço ainda aos pareceristas por suas 
observações a respeito deste trabalho, sem dúvida importantes para seu posterior desenvolvimento.

\section{Referências}

CHOMSKY, Noam. The minimalist program. Cambridge, MA: MIT Press, 1995. http://dx.doi. org/10.1017/S0272263197241070

GRIMSHAW, Jane. Locality and extended projection. Amsterdam Studies in the Theory and History of Linguistic Science Series, v. 4, p. 115-134, 2000. http://dx.doi.org/10.1075/ cilt.197.07gri

HALLE, Morris; MARANTZ, Alec. Distributed morphology and the pieces of inflection. In: HALE, Kenneth; KEYSER, Samuel Jay. The View from Building 20. Cambridge, Massachusetts: MIT Press, 1993. p. 111-176.

KAYNE, Richard. The antisymmetry of syntax, MIT Press, Cambridge, 1995.

LIBERMAN, Mark; PRINCE, Alan. On stress and linguistic rhythm. Linguistic Inquiry, v. 8, n. 2, p. 249-336, 1977.

MAZUKA, Reiko. The development of language processing strategies: a cross-linguistic study between Japanese and English. Mahwah, NJ: Erlbaum, 1998.

NESPOR, Marina; VOGEL, Irene. Prosodic Phonology. Foris: Dordrecht, 1986.

SELKIRK, Elisabeth. On Prosodic Structure and Its Relation to Syntactic Structure. Indiana University Linguistics Club, ms., 1980.

On derived domains in sentence phonology. Phonology Yearbook, v. 3, p. 371-405, 1986. http://dx.doi.org/10.1017/S0952675700000695

Recebido em 21/04/2015.

Aceito em $07 / 07 / 2015$ 